\title{
. \\ Detection of Peanut Traces in Food by an Official Food Safety Laboratory
}

\author{
Clara Tramuta ${ }^{1, *}$, Lucia Decastelli $^{1}$, Elisa Barcucci ${ }^{1}$, Francesco Ingravalle ${ }^{2}$, Sandra Fragassi ${ }^{1}$, Samantha Lupi ${ }^{1}$ \\ and Daniela Manila Bianchi ${ }^{1}$ (D)
}

1 Istituto Zooprofilattico Sperimentale del Piemonte Liguria e Valle d'Aosta-Centro di Referenza Nazionale per la Rilevazione Negli Alimenti di Sostanze e Prodotti che Provocano Allergie e Intolleranze-CReNaRiA, Via Bologna, 148, 10154 Turin, Italy; lucia.decastelli@izsto.it (L.D.); elisa.barcucci@izsto.it (E.B.); sandra.fragrassi@izsto.it (S.F.); samantha.lupi@izsto.it (S.L.); manila.bianchi@izsto.it (D.M.B.)

2 Istituto Zooprofilattico Sperimentale del Piemonte Liguria e Valle d'Aosta-S.S. Biostatistica, Epidemiologia e Analisi del Rischio (BEAR), Via Bologna, 148, 10154 Turin, Italy; francesco.ingravalle@izsto.it

* Correspondence: clara.tramuta@izsto.it; Tel.: +39-0112686225

check for updates

Citation: Tramuta, C.; Decastelli, L. Barcucci, E.; Ingravalle, F.; Fragassi, S.; Lupi, S.; Bianchi, D.M. Detection of Peanut Traces in Food by an Official Food Safety Laboratory. Foods 2022, 11, 643. https://doi.org/ 10.3390 /foods 11050643

Academic Editor: Qinchun Rao

Received: 14 January 2022

Accepted: 19 February 2022

Published: 23 February 2022

Publisher's Note: MDPI stays neutral with regard to jurisdictional claims in published maps and institutional affiliations.

Copyright: (C) 2022 by the authors. Licensee MDPI, Basel, Switzerland. This article is an open access article distributed under the terms and conditions of the Creative Commons Attribution (CC BY) license (https:// creativecommons.org/licenses/by/ $4.0 /)$.

\begin{abstract}
Food safety laboratories rely on validated methods that detect hidden allergens in food to ensure the safety and health of allergic consumers. Here we present test results for the validation and accreditation of a real-time PCR assay for the detection of peanut traces in food products. The method was tested on five classes of food matrices: bakery and pastry products, meats, ready-to-eat and dairy products, and grains and milling products. Blank samples were spiked starting with the peanut samples (Arachis hypogaea) at a concentration of $1000 \mathrm{ppm}$. Serial dilutions were then prepared with the DNA extracted from the blank samples to a final concentration of $0.5 \mathrm{ppm}$. The limit of detection in grains and milling products, ready-to-eat, meats, bakery and pastry products was $0.5 \mathrm{ppm}$ (range, Ct 27-34) and $2.5 \mathrm{ppm}$ in dairy products (range, Ct 25-34). In order to determine the exclusivity parameter of the method, the ragù matrix was contaminated with Prunus dulcis (almonds), Glycine max (soy), Sinapis alba (mustard), Apium graveolens (celery), Allium cepa (onion), Pisum sativum (peas), Daucus carota (carrots), and Theobroma cacao (cocoa); no cross-reactions were observed. The method was rated satisfactory for sensitivity (98\%), specificity $(100 \%)$, robustness, and repeatability and it was fully validated and accredited.
\end{abstract}

Keywords: food allergen; peanut; real-time PCR; validation

\section{Introduction}

The prevalence of food allergy in the Western world is estimated at $2 \%$ of adults and up to $8 \%$ of children [1]. In Europe, the protection of allergic consumers is guaranteed by European Union regulation (EU 1169/2011) [2], which governs a consumer's right to information and identifies 14 food allergens that must be listed on the packaging label. In the United States, the Food Allergen Labelling and Consumer Protection Act (FALCPA) requires that the eight major food allergens, which cause approximately $90 \%$ of food hypersensitivity reactions, are contained in any packaged food be declared under a name that is readily recognizable to consumers. The food allergens include milk, eggs, fish (bass, flounder, cod), shellfish (crab, lobster, shrimp), tree nuts (almonds, pecans, walnuts), peanuts, wheat, and soy.

The two governing rules of the polymerase chain reaction (PCR) method as it relates to labeling requirements are the general rule for the labeling of prepackaged foods and the general rule for nutrition labeling of prepackaged foods. The general rule for the labeling of prepackaged foods identifies peanuts, soybeans, wheat, shellfish, fish, eggs, milk, and tree nuts as the most problematic allergens, which are the same foods the US Food and Drug Administration (FDA) considers "major allergens". Peanuts are used widely by the food 
industry in the production of peanut butter, confections, roasted peanuts, snack products, and desserts [3].

Hypersensitivity to peanuts is a growing public health problem, and the ingestion of even small amounts can trigger a severe or sometimes fatal allergic reaction. A reaction will typically occur during the first years of life; peanut allergy is usually lifelong. Symptoms may appear within seconds of ingestion, peak by $30 \mathrm{~min}$ or develop up to $2 \mathrm{~h}$ later. The target organs of a peanut-related allergic reaction are the skin, the gastrointestinal (GI), and the respiratory tract. Skin-related symptoms include urticaria, angioedema, and occasional worsening of existing eczema. GI symptoms include abdominal pain, vomiting, and/or diarrhea. Respiratory symptoms can manifest with repetitive coughing, stridor, and wheezing. Furthermore, the cardiac and the central nervous system may also be involved in the setting of anaphylactic shock, in which diminished tissue perfusion leads to cardiac arrest and syncope [4]. In an American registry of fatal food-induced anaphylaxis, 37 of the 63 fatalities recorded over a 12-year period were caused by peanut ingestion. In the United Kingdom, 10 out of 37 food allergy fatalities recorded between 1992 and 1998 were related to peanut ingestion. A two-year prospective study in a pediatric population in the UK reported three deaths, none caused by peanut, and 55 severe or near-fatal food-allergic reactions, 10 of which caused by peanut [5].

The worldwide prevalence of peanut allergy varies between 1-2\% (United States, United Kingdom, Canada, Australia), 0.3-0.7\% (France), and 0.2-0.6\% (Denmark), while it is rare in Asia, where peanut is often absent from the list of common allergenic foods. The economic cost of food allergies, comprising peanut allergies, varies based on the study but in all cases is significant. Data from a 2012 survey estimated the economic cost of any food allergy in US children at $\$ 24.8$ billion annually, or $\$ 4184$ per child, with $\$ 4.3$ billion in direct medical costs. Hospitalization accounted for $\$ 1.9$ billion, followed by outpatient visits to an allergist (\$819 million), emergency department visits (\$764 million), and pediatrician visits (\$543 million) [6].

To date, 16 allergenic proteins in peanut have been recognized: three seed storage proteins (SSPs, Ara h 1, Ara h 2, Ara h 3) are the major peanut allergens and are considered the markers of IgE-mediated peanut allergy. To protect allergic consumers against the risk of allergic food reactions, food safety laboratories apply validated methods to detect hidden allergens in food products. DNA-based detection methods, such as real-time PCR, together with immunologically based methods, such as enzyme-linked immunosorbent assay (ELISA), are currently used to detect hidden allergens [7,8]. Although PCR does not detect proteins with allergenic potential, there is increasing interest in developing it as a supplement, or an alternative to less sensitive immunologically based methods presently considered the methods of choice.

The US FDA Foods Program Regulatory Science Steering Committee (RSSC) provides guidelines for validating analytical methods in the nucleic acid sequence-based analysis of food [9]. Method validation refers to the process of demonstrating or confirming that a method is suitable for its intended purpose; it is achieved by conducting experiments to determine performance characteristics and quantify method performance after initial method development and optimization. Method validation criteria may include sensitivity, accuracy, trueness, reproducibility and robustness, and precision.

Our Institute (IZSPLV, Istituto Zooprofilattico Sperimentale del Piemonte, Liguria e Valle d'Aosta, Turin, Italy) carries out controls and research in food safety and animal health. The Food Safety Laboratory performs analysis of samples for official microbiological controls and supports agencies in risk analysis and epidemiological outbreak investigations. The laboratory was recently selected as the Italian national reference center for the detection of food allergens and substances causing food intolerance (CReNaRiA, Centro di Referenza Nazionale per la Rilevazione negli Alimenti di Sostanze e Prodotti che provocano Allergie e Intolleranze), with a mandate to develop, validate, and accredit innovative methods for the detection of hidden allergenic substances in food products. Different from European legislation regulating food microbiology testing, which establishes the analytical approach, 
the ISO, and the methods for setting food safety criteria, there is no international legislation that stipulates required analytical testing for hidden food allergens [10]. Furthermore, commercial tests routinely used in official or private laboratories are protected by industrial secrets or patents: since users may be granted partial access to information made public by producers in the internal validation report, they need to check the performance and validate the test to obtain accreditation.

Here we describe the optimization and the validation protocol of a real-time PCR method (RT-PCR: SPECIALfinder MC Peanut, Generon) for the detection of peanut traces in food products.

\section{Materials and Methods}

\subsection{Food Matrix and Sample Preparation}

Five food categories were chosen to test the method on food models that mimic foods for human consumption. The model foods were: bakery and pastry products (chocolate cookies), meats (ragù), ready-to-eat (olivier salad), dairy products (yogurt), grains and milling products (rice and barley flour).

In order to ensure the absence of peanut in the true negative matrices, the blank samples were prepared in the laboratory using raw materials coming directly from primary production or short supply chains or that had not been transformed by the food manufacturer and used as an ingredient in a different food product. When this was not possible, the ingredient was tested to exclude the undeclared presence of the target allergen. Table 1 presents the origin of the ingredients (e.g., beans and carrots for preparing the olivier salad were collected from a family vegetable garden; beef for ragù was obtained from a portion of muscle taken during slaughtering). Blank samples were prepared using disposable equipment (trays, containers, test tubes) or washed and autoclaved (tempered glass and blades, steel cutlery, beaker, and other glassware).

Table 1. Origin of ingredients for preparation of blank samples.

\begin{tabular}{|c|c|c|c|}
\hline Matrix & True Negative Food & Ingredient & Origin \\
\hline \multirow{5}{*}{ Bakery and pastry products } & \multirow{5}{*}{ Chocolate cookies } & Corn flour & Field harvest \\
\hline & & Egg & Farm shell egg \\
\hline & & Oil & Commercial \\
\hline & & Sugar & Commercial \\
\hline & & Cocoa beans & $\begin{array}{c}\text { Commercial, negative for peanuts } \\
\text { after testing }\end{array}$ \\
\hline \multirow{2}{*}{ Grains and milling products } & \multirow{2}{*}{ Rice and barley flour } & Rice in grains & $\begin{array}{c}\text { Commercial, negative for peanuts } \\
\text { after testing }\end{array}$ \\
\hline & & Barley in grains & $\begin{array}{c}\text { Commercial, negative for peanuts } \\
\text { after testing }\end{array}$ \\
\hline \multirow{4}{*}{ Ready-to-eat } & \multirow{4}{*}{ Olivier salad } & Egg & Farm shell egg \\
\hline & & Oil & Commercial \\
\hline & & Carrot & Family vegetable garden \\
\hline & & Peas & Family vegetable garden \\
\hline \multirow[b]{2}{*}{ Dairy product } & \multirow[b]{2}{*}{ Yogurt } & Milk & Bovine farm bulk milk tank \\
\hline & & Lyophilized bacterial cultures & $\begin{array}{c}\text { Commercial Lactobacillus } \\
\text { bulgaricus and Streptococcus } \\
\text { thermophilus strains }\end{array}$ \\
\hline \multirow{4}{*}{ Meats } & \multirow{4}{*}{ Ragù } & Beef & Muscle taken at slaughtering \\
\hline & & Tomato & Family vegetable garden \\
\hline & & Onion & Family vegetable garden \\
\hline & & Carrot & Family vegetable garden \\
\hline
\end{tabular}


A portion of the true negative blank samples was spiked with power peanut (Arachis hypogaea) obtained by nitrogen freezing and then lyophilized. The spiked samples were contaminated to a concentration of $1000 \mathrm{ppm}(\mathrm{mg} / \mathrm{kg})$ to obtain high concentration spiked samples (HCSS).

\subsection{DNA Extraction}

DNA from the blank samples (10 replicates) and the spiked samples (10 replicates) for each matrix was extracted using ION Force FAST (Generon, San Prospero, MO, Italy). Briefly, $20 \mathrm{~mL}$ of solution A were added to a bottle containing $5 \mathrm{~g}$ of sample and incubated for $1 \mathrm{~h}$ at $85{ }^{\circ} \mathrm{C}$ in a water bath or in a thermomixer. After centrifugation for $10 \mathrm{~min}$ at $10,000 \mathrm{rpm}$, the aqueous supernatant was transferred to a $50-\mathrm{mL}$ bottle, and an equal amount of buffer $\mathrm{E}$ was added. The samples were vortexed and centrifuged for $10 \mathrm{~min}$ at $10,000 \mathrm{rpm}$. A set of the subnatants were added with $7.5 \mathrm{~mL}$ of buffer $\mathrm{T}$ and $20 \mu \mathrm{L}$ of glacial acetic acid. After filtering the samples in 12-mL syringes and 0.45 micron filters (this step was omitted for the yogurt matrix), the columns on the vacuum chamber were assembled, and the vacuum pump was operated for column purification. Two successive washes were then performed using $1 \mathrm{~mL}$ of buffer P. The column was centrifuged for $5 \mathrm{~min}$ at $7000 \mathrm{rpm}$ to remove ethanol residues. DNA was eluted with $100 \mu \mathrm{L}$ of buffer $\mathrm{D}$ after centrifugation at $500 \mathrm{rpm}$ for $30 \mathrm{~s}$ and at $14,000 \mathrm{rpm}$ for $5 \mathrm{~min}$.

\subsection{Real-Time PCR Procedure}

DNA extracts $(5 \mu \mathrm{L})$ were added to $15 \mu \mathrm{L}$ of the reaction mix (RT-PCR SPECIAL finder MC Peanut, Generon, San Prospero, MO, Italy. The PCR system targets a sequence encoding rRNA with a length of $90 \mathrm{bp}$ in multiple copies in cells. The amplified DNA segments were detected with a beacon probe labeled with the fluorophore FAM (peanut) and fluorophore HEX (internal amplification control) to monitor the quality of reaction performance and quencher BHQ-1.

Real-time PCR was performed on a CFX96 real-time PCR system (Bio-Rad, Richmond, CA, USA) according to the cycling protocol: initial step at $95^{\circ} \mathrm{C}$ for $3 \mathrm{~min}$, followed by 35 cycles of denaturation at $95{ }^{\circ} \mathrm{C}$ for $5 \mathrm{~s}$, annealing at $60^{\circ} \mathrm{C}$ for $10 \mathrm{~s}$, and extension at $72{ }^{\circ} \mathrm{C}$ for $20 \mathrm{~s}$.

\subsection{Determination of Specificity}

Method specificity was checked in silico by comparing sequences on BLASTn of non-target allergens, animal, and vegetable species. The primers were tested for complementarity with the sequences of the following non-target substances (allergens): almond, barley, Brazil nut, buckwheat, cashew, celeriac, celery, coconut, durum wheat, einkorn, hazelnut, kamut, lupin, macadamia nut, mustard, oats, pecan nut, pine nut, pistachio, rye, sesame, soft wheat, soy, walnut; clam (Venus gallina); hake (Merluccius merluccius); lobster (Nephrops norvegicus); mussel (Mytilus edulis); prawn (Penaeus vannamei); salmon (Oncorhynchus kisutch); sea bream (Sparus aurata); squid (Loligo edulis); yellowfin tuna (Thunnus albacares); animal species: bison, wild boar, buffalo, cow, chicken, donkey, duck, goat, goose, horse, quail, rabbit, sheep, swine, turkey; vegetable species: apple, apricot, arugula, egg plant, banana, basil, bean, black pepper, blackberry, broccoli, brussels sprouts, black cabbage, cacao, carrot, cauliflower, chard, cherry, chestnut, chickpea, clementine, corn, cucumber, currant, fennel, fig, flax, garlic, ginger, grapefruit, grapevine, kiwi, laurel, lemon, lentil, mahaleb, marrow (zucchini), mushroom, mango, marjoram, olive, onion, orange, oregano, parsley, pea, peach, pear, pepper, pineapple, pink peppercorn, plum, pomelo, poplar, poppy, potato, radish, rapeseed, raspberry, red cabbage, rice, saffron, savoy cabbage, shallot, spinach, strawberry, sunflower, tangerine, tarragon, thyme, tomato, turnip greens. Primer specificity was then tested by amplification of the DNA extracted from the blank samples (10 replicates for each matrix, for a total of 50 samples). In order to determine exclusivity of the method, the extracted DNA of the ragù matrix contaminated with Prunus dulcis (almonds), Glycine max (soy), Sinapis alba (mustard), Apium graveolens (celery), Allium 
cepa (onion), Pisum sativum (peas), Daucus carota (carrots), and Theobroma cacao (cocoa) was amplified.

\subsection{Determination of Sensitivity}

A portion of the true negative blank samples was spiked with peanut powder (Arachis hypogaea). The spiked samples were contaminated to a concentration of $1000 \mathrm{ppm}(\mathrm{mg} / \mathrm{kg})$ (HCSS). Ten replicates for each matrix (total 50 replicates) of HCSS were processed for DNA extraction as described above. DNA extracted from the HCSS at the initial concentration of $1000 \mathrm{ppm}$ was diluted (1000 ppm, $250 \mathrm{ppm}, 100 \mathrm{ppm}, 50 \mathrm{ppm}, 25 \mathrm{ppm}, 10 \mathrm{ppm}, 5 \mathrm{ppm}$, $2.5 \mathrm{ppm}, 1 \mathrm{ppm}, 0.5 \mathrm{ppm}$ ) with the DNA extracted from the blank samples to a final concentration of $0.5 \mathrm{ppm}$. DNA extracts $(5 \mu \mathrm{L})$ were added to $15 \mu \mathrm{L}$ of the reaction mix (RTPCR SPECIALfinder MC Peanut, Generon, San Prospero, MO, Italy). Real-time PCR was performed on a CFX96 real-time PCR system (Bio-Rad) according to the cycling protocol: initial step at $95{ }^{\circ} \mathrm{C}$ for $3 \mathrm{~min}$, followed by 35 cycles of denaturation at $95{ }^{\circ} \mathrm{C}$ for $5 \mathrm{~s}$, annealing at $60^{\circ} \mathrm{C}$ for $10 \mathrm{~s}$, and extension at $72{ }^{\circ} \mathrm{C}$ for $20 \mathrm{~s}$.

DNA was extracted from spiked ragù samples and diluted to a theoretical concentration of 0.5, 5, 50, and $500 \mathrm{ppm}$ and then tested with the RT-PCR SPECIALfinder MC Peanut, Generon (San Prospero, MO, Italy) to verify the correspondence between the serial dilutions.

The $\mathrm{Ct}$ values obtained from the analysis were summarized by descriptive statistics (mean, standard deviation (sd), median). We also checked for differences between the $\mathrm{Ct}$ values from different matrices (cookies, flour, olivier salad, ragù, yogurt) using the nonparametric Kruskal-Wallis test. Single pairwise comparisons between matrices were evaluated using the two-sample Wilcoxon (Mann-Whitney) rank-sum test. A non-parametric approach instead of the ANOVA accordingly to the normality and homoskedasticity of the Ct distributions.

Performance of the RT-PCR SPECIALfinder MC Peanut (San Prospero, MO, Italy) on unknown samples was tested on samples from an international proficiency test organized by an ISO 17043:2010-accredited institute [11]. The trial included two blind food samples to be analyzed by the participants according to internal procedures: DNA was extracted according to the procedure described above; amplification was performed following the protocol used in the validation trial on a CFX96 real-time PCR system (Bio-Rad, Richmond, CA, USA).

\subsection{Robustness}

Method robustness is usually determined by measuring its capacity to remain unaffected by small but deliberate deviations from the experimental conditions described in the protocols. Robustness was determined by changing the real-time instrument: $5 \mu \mathrm{L}$ DNA extracts of the spiked chocolate cookies were added to $15 \mu \mathrm{L}$ of reaction mix and amplified on a 7500 Fast Dx Real-Time PCR system (Applied Biosystems, Foster City, CA, USA) at the same temperature and time conditions used on the CFX96 real-time PCR system (Bio-Rad, Richmond, CA, USA), with the initial step at $95^{\circ} \mathrm{C}$ for $3 \mathrm{~min}$, followed by 35 cycles of denaturation at $95^{\circ} \mathrm{C}$ for $5 \mathrm{~s}$, annealing at $60^{\circ} \mathrm{C}$ for $10 \mathrm{~s}$, and extension at $72{ }^{\circ} \mathrm{C}$ for $20 \mathrm{~s}$

\subsection{Repeatability}

To test repeatability of the SPECIALfinder MC Peanut kit (San Prospero, MO, Italy), the relative standard deviation repeatability (RSDr, of results obtained by the same method, by the same analyst, in the same laboratory, with the same equipment, on the same samples) was statistically calculated on 10 replicates at the limit of detection (LOD) concentration for each matrix. 


\section{Results}

\subsection{Specificity}

The in silico test of the sequences of primers and probes excluded cross-reactivity with all allergens, animal and vegetable species, and with potentially co-occurring species/varieties. The results showed $100 \%$ specificity of the PCR method, as tested by amplification of the DNA extracted from the blank samples. All 50 blank samples tested negative for the target allergen; no amplification signals in FAM or amplification signals in HEX were noted. In order to determine the exclusivity parameter of the method, the ragù matrix was contaminated with Prunus dulcis (almonds), Glycine max (soy), Sinapis Alba (mustard), Apium graveolens (celery), Allium cepa (onion), Pisum sativum (peas), Daucus carota (carrots), and Theobroma cacao (cocoa) and no cross-reactions were observed.

\subsection{Sensitivity}

The method sensitivity was $98 \%$ (Table 2): the LOD in grains and milling products, ready-to-eat, meats, bakery, pastry products was $0.5 \mathrm{ppm}$ and $2.5 \mathrm{ppm}$ in dairy products. The threshold cycle $(\mathrm{Ct})$ to find the lowest value that allows high fluorescence levels and the lowest possible LOD for the PCR was between 27 and 34 (matrix LOD 0.5 ppm) and between 25 and 34 (yogurt LOD 2.5 ppm) (Table 2). Real-time PCR Ct of the food matrices spiked to a concentration 10-fold the LOD is presented in Table 3. The standard curve of the cycle threshold $(\mathrm{Ct})$ calculated from the serial dilutions of DNA extracted from the ragù spiked sample is shown in Figure 1.

Table 2. Real-time PCR cycle threshold (Ct) for spiking food matrix to LOD.

\begin{tabular}{cccccc}
\hline Extraction & Cookies & Ragù & Flour & Olivier Salad & Yogurt \\
\hline 1 & 28.07 & 29.34 & 28.69 & 28.42 & 32.05 \\
\hline 2 & 27.04 & 30.28 & 28.54 & 28.98 & 33.52 \\
\hline 3 & 27.73 & 29.09 & 29.16 & 28.32 & 31.63 \\
\hline 4 & 28.61 & Not detected & 30.29 & 30.83 & 30.04 \\
\hline 5 & 31.27 & 31.24 & 29.37 & 32.36 & 31.27 \\
\hline 6 & 28.07 & 39.62 & 29.48 & 27.26 & 25.9 \\
\hline 7 & 27.71 & 28.38 & 29.27 & 27.58 & 31.24 \\
\hline 8 & 28.27 & 29.08 & 28.81 & 28.16 & 31.49 \\
\hline 9 & 28.04 & 32.04 & 28.54 & 27.62 & 32.38 \\
\hline 10 & 28.36 & 28.46 & 28.7 & 29.63 & 32.36 \\
\hline Mean & 28.32 & 29.73 & 29.09 & 28.92 & 31.19 \\
\hline Sd & 1.12 & 1.24 & 0.55 & 1.61 & 2.07 \\
\hline Median & 28.07 & 29.34 & 28.99 & 28.37 & 31.56 \\
\hline Minimum & 27.04 & 28.38 & 28.54 & 27.26 & 25.90 \\
\hline Maximum & 31.27 & 32.04 & 30.29 & 32.36 & 33.52 \\
\hline
\end{tabular}


Table 3. Real-time PCR cycle threshold (Ct) for spiking food matrix to 10XLOD.

\begin{tabular}{cccccc}
\hline Extraction & Cookies & Ragù & Flour & Olivier Salad & Yogurt \\
\hline 1 & 25.09 & 25.67 & 25.85 & 25.4 & 27.73 \\
\hline 2 & 24.3 & 26.53 & 26.56 & 25.66 & 29.27 \\
\hline 3 & 24.7 & 25.23 & 26.22 & 25.35 & 27.96 \\
\hline 4 & 25.54 & 32.05 & 27.05 & 27.68 & 26.44 \\
\hline 5 & 28.19 & 27.12 & 26.21 & 29.47 & 25.71 \\
\hline 6 & 24.65 & 26.04 & 27.22 & 24.29 & 22.62 \\
\hline 7 & 25.03 & 25.01 & 26.03 & 24.43 & 28.27 \\
\hline 8 & 25.17 & 25.51 & 26 & 25.28 & 27.85 \\
\hline 9 & 25.58 & 27.6 & 25.54 & 24.67 & 28.52 \\
\hline 10 & 24.88 & 25.21 & 26.14 & 26.54 & 28.65 \\
\hline Mean & 25.31 & 26.60 & 26.28 & 25.88 & 27.30 \\
\hline Sd & 1.08 & 2.10 & 0.52 & 1.62 & 1.95 \\
\hline Median & 25.06 & 25.86 & 26.18 & 25.38 & 27.91 \\
\hline Minimum & 24.30 & 25.01 & 25.54 & 24.29 & 22.62 \\
\hline Maximum & 28.19 & 32.05 & 27.22 & 29.47 & 29.27 \\
\hline
\end{tabular}

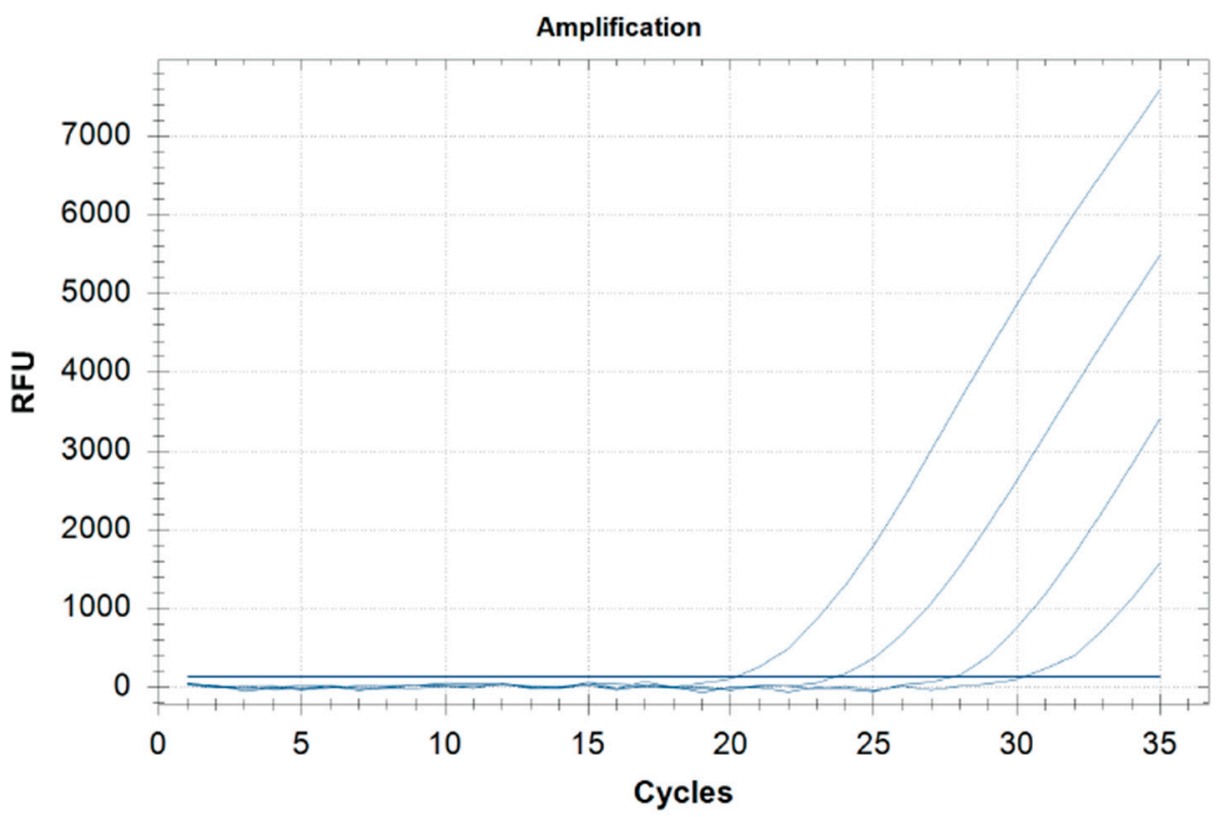

Figure 1. Standard curve of real-time PCR obtained by analyzing serial dilutions of DNA extracted $(0.5,5,50,500 \mathrm{ppm})$ from the ragù spiked samples (range, $0.5-500 \mathrm{ppm}$ ).

The results of the descriptive statistics reported in Tables 2 and 3 suggest differences both in Sd (flour is lower than the other matrices) and in mean and median (cookies often are the lowest and yogurt often is the highest).

The Kruskal-Wallis test confirms differences between matrices, both at LOD level $(p=0.0008)$ and at 10XLOD level $(p=0.0064)$.

Table 4 shows the $p$-value $(p)$ obtained from the two-sample Wilcoxon (Mann-Whitney) rank-sum test for which pairwise comparisons. 
Table 4. Pairwise comparisons with $p$-value $(p)$ and significance level of the two-sample Wilcoxon (Mann-Whitney) rank-sum test.

\begin{tabular}{|c|c|c|c|c|c|c|}
\hline \multicolumn{3}{|c|}{ Pairwise Comparisons } & \multirow{2}{*}{$\begin{array}{c}\text { LOD } \\
p \text {-Value }(p) \\
0.4055\end{array}$} & & \multirow{2}{*}{$\begin{array}{c}\begin{array}{c}\text { 10XLOD } \\
p \text {-Value }(p)\end{array} \\
0.4057\end{array}$} & \\
\hline Cookies & vs. & Olivier salad & & & & \\
\hline Cookies & vs. & Flour & 0.0040 & $* *$ & 0.0036 & ** \\
\hline Cookies & vs. & Ragù & 0.0042 & $* *$ & 0.0233 & $*$ \\
\hline Cookies & vs. & Yogurt & 0.0046 & $* *$ & 0.0082 & $* *$ \\
\hline Olivier salad & vs. & Flour & 0.2263 & & 0.0963 & \\
\hline Olivier salad & vs. & Ragù & 0.1025 & & 0.3643 & \\
\hline Olivier salad & vs. & Yogurt & 0.0140 & * & 0.0412 & $*$ \\
\hline Flour & vs. & Ragù & 0.4140 & & 0.4963 & \\
\hline Flour & vs. & Yogurt & 0.0032 & $* *$ & 0.0343 & * \\
\hline Ragù & vs. & Yogurt & 0.0199 & * & 0.0696 & \\
\hline
\end{tabular}

Results of blind samples analyzed in the interlaboratory trial were satisfactory, according to the final report published by the organizer. The two blind samples were reported as negative and positive, respectively. The trial was designed as a qualitative approach, as required for accreditation.

\subsection{Robustness}

The robustness test showed no statistically significant discrepancies between the two instruments, while the $\mathrm{Ct}$ of the single reactions varied only slightly (mean $\mathrm{Ct}, 28.03$; range, 28-32.07). Congruent results for all samples indicated that the method is robust.

\subsection{Repeatability}

The assay exhibited a high degree of repeatability for the blank samples and the spiked samples contaminated at the LOD concentration. The RSDr within the test did not exceed $25 \%$.

\section{Discussion}

Peanut ingestion is a major cause of food allergy reactions. A diet devoid of protein is the only way allergic people can prevent unwanted exposure. Correct food product labeling is fundamental for ensuring the protection of allergic consumers. Recent Italian studies on the presence of undeclared allergens in food products underscore the importance of food labeling to protect allergic individuals [12-14]. Regulation EU No. 1169/2011 [2] does not identify official analytical methods for the detection of undeclared food allergens, nor has the scientific community identified a universal threshold for each allergenic protein that may be considered safe for allergic consumers. The development of rapid and sensitive methods for the detection of hidden allergens in foods is therefore of significant regulatory interest.

The two most widely used methods for the detection of food allergens are ELISAbased and PCR-based approaches [15-17]. Some matrices can interfere with ELISA or can cause cross-reactivity. Limitations to the use of ELISA regard cooked or heated products because the protein molecules are denatured or broken down during heat treatment, which renders the allergens undetectable by specific antibodies [18]. By comparison, PCR methods perform better in cooked products as the DNA is less sensitive to heating than proteins. Nonetheless, what matters is that it is the proteins that trigger an allergic reaction. Regardless of the approach a laboratory adopts, analytical methods for food control must be validated before their use in food control laboratories, both official and business operators. 
The methods must be validated before they can be applied in complex matrices such as high-fat, dairy, or multi-ingredient foods.

Here we report the test results for the validation and accreditation of a real-time PCR assay of peanut traces in complex food matrices. The technique has the advantage that it is reliable, specific, sensitive, and rapid. As such, it can be used to detect trace amounts of peanut in food products. The food matrices were carefully selected to be representative of samples commonly collected during official monitoring in consumer protection. The food samples were prepared with ingredients that might be accidentally contaminated by peanuts; this was performed to mimic the variety of food matrices and thus cover a wide range of samples. In addition, complex food matrices were selected to mimic realworld situations in a food analysis laboratory. Prior to developing the real-time PCR, we evaluated the DNA extraction yields in complex matrices with low DNA content (yogurt and olivier salad). These two matrices are known to inhibit PCR because of lipids (e.g., oil and eggs) or require ad hoc extraction protocols in order to increase their yield. We obtained satisfactory results by optimizing the extraction protocol for these matrices. The sensitivity of the real-time PCR method was a LOD of $0.5 \mathrm{ppm}$ for bakery products, milling products, ready-to eat foods, and meat products. Although dairy products have a low DNA content, the real-time PCR had a LOD of $2.5 \mathrm{ppm}$ in the ten replicates of this matrix class and was considered satisfactory. These limits are compatible with current international regulations, which, however, have not set a quantitative criterion for the allergens we tested in this study.

The statistical analysis carried out to check Cts differences among various food categories confirmed the importance of a multi-matrices validation: in the case of the quantitative approach, this variability should be taken into account.

During validation of an analytical method, evaluation of robustness is an essential step to check its capacity to remain unaffected by small deviations from experimental conditions described in the procedure. According to the US FDA Foods Program Regulatory Science Steering Committee (RSSC) [9], the type of technical instruments (brands and models) and the concentration of reagents (probe, primers, dNTPs, salts) should be tested as factors that can potentially affect test robustness. In our study and in studies on patented tests, the most important factor in robustness testing is that the thermal cycler brand or model is different from the one on which the producers optimized the test.

Official and private laboratories performing food allergen detection analysis typically use commercial tests in which specifics of method set up (e.g., primers) are protected by patents. This poses a limitation for laboratories.

\section{Conclusions}

The real-time PCR SPECIALfinder kit for the detection of peanut traces in food products proved easy to use and provided a rapid response within less than $50 \mathrm{~min}$. Method accuracy was rated satisfactory for sensitivity $(98 \%)$ and specificity $(100 \%)$. Our results show that the method has been sufficiently validated and accredited. Furthermore, it was found adequate for the needs of an analytical laboratory, as it meets the purpose for which it was applied.

Author Contributions: Conceptualization, C.T. and D.M.B.; methodology, C.T. and D.M.B.; software, F.I.; validation, C.T. and D.M.B.; formal analysis, C.T., E.B., S.F. and S.L.; investigation, C.T., E.B., S.F. and S.L.; resources, D.M.B. and L.D.; data curation, C.T., F.I., D.M.B. and L.D.; writing-original draft preparation, C.T. and D.M.B.; writing-review and editing, C.T., D.M.B. and F.I.; visualization, C:T., D.M.B. and L.D.; supervision, D.M.B., C.T. and L.D.; project administration, D.M.B. and L.D.; funding acquisition, D.M.B. and L.D. All authors have read and agreed to the published version of the manuscript.

Funding: This research received no external funding.

Data Availability Statement: Not applicable.

Conflicts of Interest: The authors declare no conflict of interest. 


\section{References}

1. Worm, M.; Timmermans, F.; Moneret-Vautrin, A.; Muraro, A.; Malmheden Yman, I.I.; Lövik, M.; Hattersley, S.; Crevel, R. Towards a European registry of severe allergic reactions: Current status of national registries and future needs. Allergy 2010, 65, 671-680. [CrossRef] [PubMed]

2. Regulation (EU) No. 1169/2011 of the European Parliament and of the Council of 25 October 2011 on the provision of food information to consumers. OJEU 2011, 304, 18-63. Available online: https: / / eur-lex.europa.eu/LexUriServ /LexUriServ.do?uri= OJ:L:2011:304:0018:0063:en:PDF (accessed on 25 October 2011).

3. Hird, H.; Lloyd, J.; Goodier, R.; Brown, J.; Reece, P. Detection of peanut using real-time polymerase chain reaction. Eur. Food Res. Technol. 2003, 217, 265-268. [CrossRef]

4. Patel, R.; Koterba, A.P. Peanut Allergy; StatPearls Publishing: Treasure Island, FL, USA, 2022. Available online: https:/ / pubmed ncbi.nlm.nih.gov/30860761/ (accessed on 11 July 2021).

5. European Food Safety Authority. Scientific Opinion on the evaluation of allergenic foods and food ingredients for labelling purposes. EFSA J. 2014, 12, 3894.

6. Cannon, H.E. The Economic Impact of Peanut Allergies. Am. J. Manag. Care. 2018, 24, S0.

7. Garino, C.; De Paolis, A.; Coïsson, J.D.; Bianchi, D.M.; Decastelli, L.; Arlorio, M. Sensitive and specific detection of pine nut (Pinus spp.) by real-time PCR in complex food products. Food Chem. 2016, 194, 980-985. [CrossRef] [PubMed]

8. Bianchi, D.M.; Maurella, C.; Gallina, S.; Gorrasi, I.S.R.; Caramelli, M.; Decastelli, L. Analysis of Gluten Content in Gluten-Free Pizza from Certified Take-Away Pizza Restaurants. Foods 2018, 7, 180. [CrossRef] [PubMed]

9. FDA Foods Program Regulatory Science Steering Committee (RSSC). Guidelines for the Validation of Analytical Methods for Nucleic Acid Sequence-Based Analysis of Food, Feed, Cosmetics and Veterinary Products; U.S. Food and Drug Administration: White Oak, MD, USA, 2020; pp. 1-39. Available online: https:/ / www.fda.gov/media/121751/download (accessed on 20 October 2020).

10. Commission Regulation (EC) No 2073/2005 on microbiological criteria for foodstuffs. OJEU 2005, 338, 1-26. Available online: https:/ / www.fsai.ie/uploadedFiles/Reg2073_2005(1).pdf (accessed on 22 December 2005).

11. ISO/IEC 17043:2010. General Requirements for Proficiency Testing. Available online: https:/ /www.mitoeagle.org/index.php/ ISO/IEC_17043:2010_General_requirements_for_proficiency_testing (accessed on 2 February 2010).

12. Barbaro, A.; Rubinetti, F.; Galleggiante Crisafulli, A.; Radaelli, M.C.; Chiavacci, L.; Bianchi, D.M.; Adriano, D.; Zuccon, F.; Fragassi, S.; Buonincontro, G.; et al. Food Allergens: State of the Art in Piedmont Region in the Period 2011-2012. Ital. J. Food Saf. 2014, 6, 1700. [CrossRef] [PubMed]

13. Bianchi, D.M.; Adriano, D.; Astegiano, S.; Gallina, S.; Caramelli, M.; Decastelli, L. Egg and milk proteins as hidden allergens in food: 5year results of monitoring in Piedmont. J. Food Prot. 2016, 79, 1583-1587. [CrossRef] [PubMed]

14. Decastelli, L.; Arioli, F.; Bianchi, D.M.; Barbaro, A.; Nobile, M.; Panseri, S.; Chiesa, L.M. An Italian survey of undeclared allergens in food over the years 2014-2018. Food Addit. Contam. Part B Surveill. 2020, 13, 115-120. [CrossRef] [PubMed]

15. Renčová, E.; Piskatá, Z.; Kostelníková, D.; Tremlová, B. Simultaneous detection of peanut and hazelnut allergens in food matrices using multiplex PCR method. Acta Vet. Brno. 2014, 83, S77-S83. [CrossRef]

16. García, A.; Madrid, R.; García, T.; Martín, R.; González, I. Detection of Food Allergens by Taqman Real-Time PCR Methodology. Methods Mol. Biol. 2017, 1592, 95-108. [PubMed]

17. Pandey, A.K.; Varshney, R.K.; Sudini, H.K.; Pandey, M.K. An Improved Enzyme-Linked Immunosorbent Assay (ELISA) Based Protocol Using Seeds for Detection of Five Major Peanut Allergens Ara h 1, Ara h 2, Ara h 3, Ara h 6, and Ara h 8. Front. Nutr. 2019, 6, 68. [CrossRef] [PubMed]

18. Madrid, R.; García-García, A.; Cabrera, P.; González, I.; Martín, R.; García, T. Survey of Commercial Food Products for Detection of Walnut (Juglans regia) by Two ELISA Methods and Real Time PCR. Foods 2021, 10, 440. [CrossRef] [PubMed] 